\title{
Explaining long-range fluid pressure transients caused by oilfield wastewater disposal using the hydrogeologic principle of superposition
}

\author{
Ryan M. Pollyea
}

4 Department of Geosciences, Virginia Polytechnic Institute and State University, Blacksburg, 5 VA, USA

6 Corresponding author: Ryan M. Pollyea (rpollyea@,vt.edu)

$7 \quad$ Keywords

8 Salt water disposal; wastewater; earthquake; injection wells; numerical modeling

10 Abstract

11 Injection-induced earthquakes are now a regular occurrence across the midcontinent United States.

12 This phenomenon is primarily caused by oilfield wastewater disposal into deep geologic

13 formations, which induces fluid pressure transients that decrease effective stress and trigger

14 earthquakes on critically stressed faults. It is now generally accepted that the cumulative effects of

15 multiple injection wells may result in fluid pressure transients migrating $20-40 \mathrm{~km}$ from well

16 clusters. However, one recent study found that oilfield wastewater volume and earthquake

17 occurrence are spatially cross-correlated at length-scales exceeding $100 \mathrm{~km}$ across Oklahoma.

18 Moreover, researchers recently reported observations of increasing fluid pressure in wells located

$19 \sim 90 \mathrm{~km}$ north of the regionally expansive oilfield wastewater disposal operations at the Oklahoma-

20 Kansas border. Thus, injection-induced fluid pressure transients may travel much longer distances

21 than previously considered possible. This study utilizes numerical simulation to demonstrate how

22 the hydrogeologic principle of superposition reasonably explains the occurrence of long-range

23 pressure transients during oilfield wastewater disposal. The principle of superposition states that

24 the cumulative effects of multiple pumping wells are additive and results from this study show that

25 just nine high-rate injection wells drives a 10-kPa pressure front to radial distances exceeding 70 
$26 \mathrm{~km}$ after 10 years, regardless of basement permeability. These results yield compelling evidence

27 that superposition is a plausible mechanistic process to explain long-range pressure accumulation 28 and earthquake-triggering in Oklahoma and Kansas. 
30 The central and eastern United States (CEUS) averaged $\sim 19$ magnitude-3 or greater (M3+)

31 earthquakes per year before 2009 (Fig. 1, blue circles), but this average rate exceeded 400 per year

32 between 2009 and 2018 (Fig. 1, red circles). This 20-fold increase in the M3+ earthquake rate is

33 caused by oilfield wastewater disposal in deep injection wells, which induces fluid pressure

34 transients that trigger earthquakes (Keranen et al., 2014; Keranen et al., 2013; Ellsworth, 2013).

35 Injection-induced earthquakes have been

36 reported in Wyoming, Colorado, New

37 Mexico, Texas, Ohio, Kansas, and

38 Arkansas (NRC, 2013; Weingarten et al.,

39 2015), but they are most pronounced in

40 Oklahoma, where the rate of $\mathrm{M} 3+$

41 earthquakes increased from $\sim 1$ per year

42 before 2009 to over 2.5 per day in 2015

43 (Pollyea et al., 2018a). The rapid onset of

44 seismicity in Oklahoma led to a number of

45 regulatory changes, which, in combination

46 with declining prices in the oil and gas

47 markets, have been attributed to declining

48 earthquake frequency since 2015.

49 Nevertheless, Oklahoma experienced three

50 M5+ earthquakes in 2016 and there were

$51412 \mathrm{M} 3+$ earthquakes across the CEUS in

522018.

53 Injection-induced earthquakes are

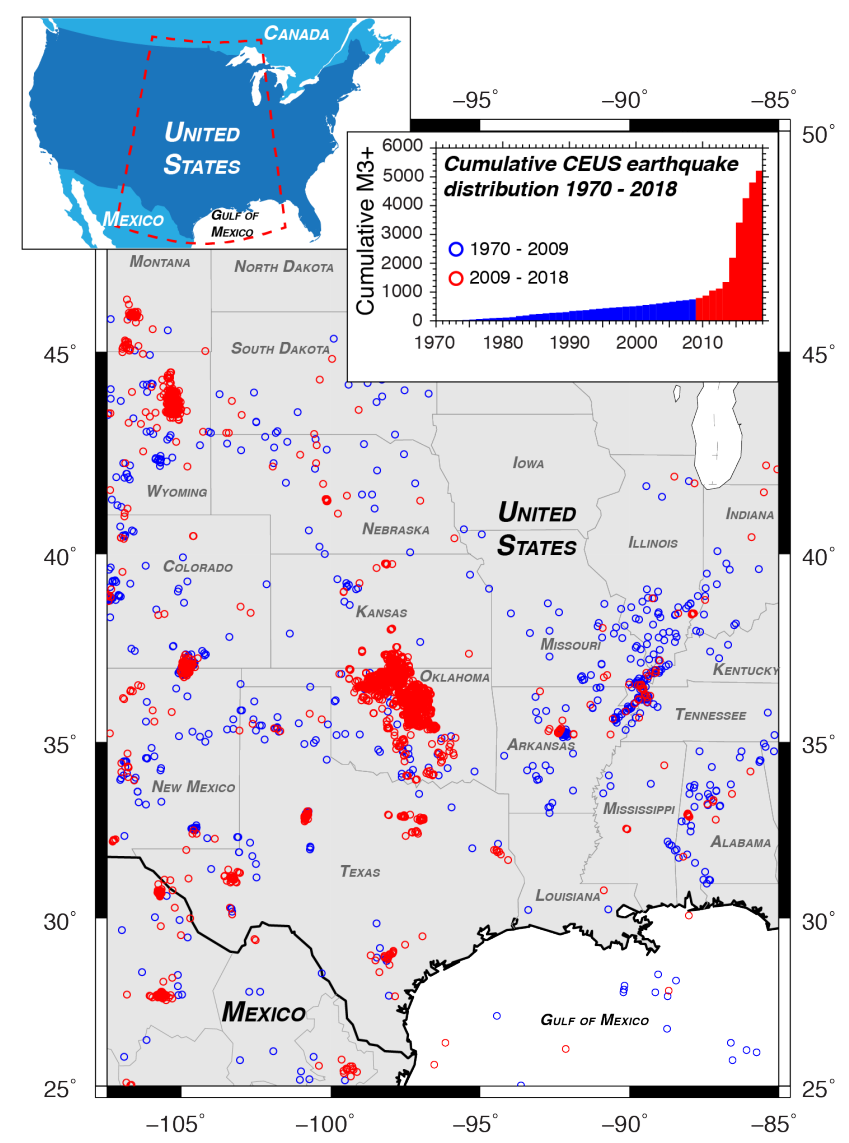

Figure 1: Spatial and temporal (right inset) distribution M3+ earthquakes in the central and eastern United States from January 1, 1970 to December 31, 2018. Data from USGS ComCat database (USGS, 2019). Figure design adapted from Figure 2 in Ellsworth (2013).

54 reasonably explained by the application of effective stress theory to the Mohr-Coulomb failure 55 criterion (NRC, 2013). Specifically, the effective normal stresses acting on a fault decreases in equal proportion to a rise in fluid pressure less any poro-elastic relaxation (Zoback \& Hickman,

57 1982). Given a sufficient rise in pore fluid pressure within faults optimally aligned to the regional 58 stress field, the effective normal stress may drop below the Mohr-Coulomb failure threshold 59 triggering the release of previously accumulated strain energy into the surrounding rock (Raleigh 
et al., 1976; Hubbert \& Willis, 1957). The seismic moment of injection-induced earthquakes is governed by fault shear modulus, rupture area, and displacement, while their occurrence is largely controlled by interactions between injection-induced fluid pressure transients and faults optimally aligned with the regional stress field (Walsh \& Zoback, 2015; Shapiro et al., 2011).

The linkage between oilfield wastewater disposal, fluid pressure transients, and earthquake occurrence in Oklahoma, USA, was originally reported by Keranen et al. (2014). This landmark study showed that high-rate wastewater injection wells near Oklahoma City caused a pressure front to migrate over $40 \mathrm{~km}$ from the well cluster and the temporal progression of this pressure front accurately matched the 2011 Jones earthquake swarm. Similarly, Goebel et al. (2017) showed that the 2016 M5.1 earthquake sequence in Fairview, Oklahoma likely resulted from wastewater injection wells located $\sim 40 \mathrm{~km}$ away, although this study, as well as Goebel \& Brodsky (2018), suggests that poro-elastic stress transfer may also trigger earthquakes at long radial distances from injection wells. Nevertheless, history-matching groundwater models are now widely implemented to link oilfield wastewater disposal with earthquake swarms, e.g., in Milan, Kansas (Hearn et al., 2018), Greeley, Colorado (Brown et al., 2017), Dallas-Fort Worth, Texas (Ogwari et al., 2018), and Guthrie, Oklahoma (Schoenball et al., 2018). These studies show that oilfield wastewater disposal causes pressure transients $(\geq 10 \mathrm{kPa})$ that induce earthquakes at lateral distances of 20 $40 \mathrm{~km}$ away from injection wells.

At the regional-scale, several recent studies focusing on central Oklahoma and southern Kansas show that injection-induced pressure transients may travel much farther distances than 80 previously considered possible. For example, Langenbruch et al. (2018) developed a regionalscale model of oilfield wastewater disposal that shows injection-induced pressure transients may extend 50+ km north of the well fields located near the border separating Oklahoma and Kansas.

83 Similarly, Pollyea et al. (2018a) presented a geostatistical analysis showing that earthquake occurrence and wastewater disposal volume are spatially cross-correlated at length-scales exceeding $100 \mathrm{~km}$. This latter study was disputed in the media because the geostatistical correlations do not explain the process responsible for this long-range phenomenon (Wilmoth, 2018); however, Peterie et al. (2018) later reported observations of increasing fluid pressure in deep monitoring wells, as well as earthquake swarms as far away as $90 \mathrm{~km}$ from high-rate injection wells at the Kansas-Oklahoma border (Peterie et al., 2018). In an explicit acknowledgement of 
91 diffusion from cumulative disposal to the south likely induced earthquakes much farther than

92 previously documented from individual injection wells." While the scientific community generally

93 agrees that "cumulative disposal" from numerous high-rate wastewater injection wells is driving

94 pressure transients over extraordinary lateral distances, the mechanistic process responsible for 95 these cumulative effects has not been clearly documented in the literature. As a consequence, 96 statistical analyses of long-range earthquake triggering (Pollyea et al., 2018a) are met with 97 skepticism (Wilmoth, 2018) and observations of long-range fluid pressure accumulation do not 98 have a defensible mechanistic explanation (Peterie et al., 2018).

This study implements high-fidelity, multi-physics numerical simulation to show that the 100 hydrogeological principle of superposition reasonably explains recent reports of long-range 101 pressure transients caused by oilfield wastewater disposal. As a mechanistic process, the principle 102 of superposition simply states that pressure transients from closely-spaced injection wells will 103 merge to locally increase the hydraulic gradient, thus driving fluid pressure much longer distances 104 than is possible from wells operating in isolation.

\section{Methods}

106 To understand the hydrogeology of long-range pressure transients during oilfield wastewater 107 disposal, this study models several hypothetical wastewater injection scenarios using 108 characteristics of the Anadarko Shelf geologic province of north-central Oklahoma. Between 2011 109 and 2015, this region experienced rapid increases in both oilfield wastewater disposal and 110 earthquake occurrence (Pollyea et al., 2019; Pollyea et al., 2018b). The primary target reservoir 111 for oilfield wastewater disposal is the Arbuckle formation, which is in direct hydraulic 112 communication with the underlying Precambrian basement (Johnson, 1991). The geologic model 113 reproduces the Arbuckle formation from 1,900 - 2,300 m depth overlying the Precambrian 114 basement from 2,300 $\mathrm{m}-10,000 \mathrm{~m}$ depth. The model domain comprises a $200 \mathrm{~km} \times 200 \mathrm{~km}$ 115 lateral extent; however, four-fold symmetry is invoked to reduce the simulation grid to a lateral 116 extent of $100 \mathrm{~km}$ in each direction. As a result, the $100 \mathrm{~km} \times 100 \mathrm{~km} \times 8.1 \mathrm{~km}$ volume is modeled 117 as a three-dimensional unstructured grid comprising 1,278,613 grid cells with local grid refinement 

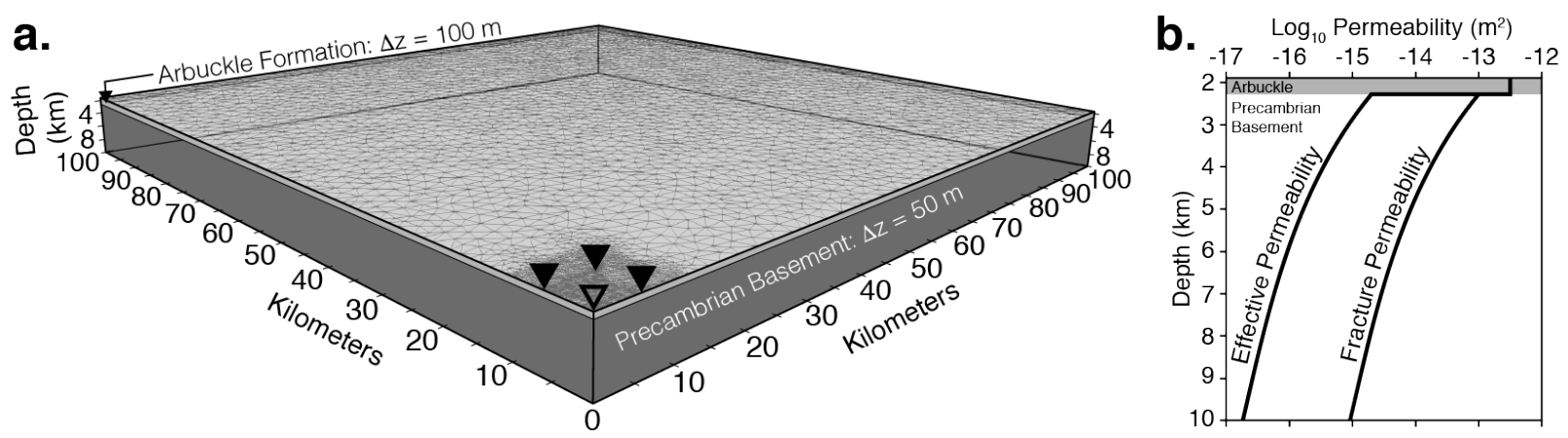

Figure 2: Schematic illustration of the (a) model domain and (b) permeability structure. The conceptual geologic model represents the Arbuckle formation from 1,900 to 2,300 m depth and Precambrian basement from 2,300 m to $10,000 \mathrm{~m}$ depth. The model is discretized as an unstructured grid comprising 1,278,613 grid cells with grid refinement near the injection wells (inverted triangles). For the single-well model only the central well is operating (open triangle). The Precambrian basement is modeled as a dual continuum with 98 vol.\% matrix and 2 vol $\%$ fracture. b presents the fracture permeability and volume-weighted effective permeability. Note that the model domain invokes four-fold symmetry, so the one-quarter domain accounts for the effects of nine injection wells when all wells are operating.

118 near the injection wells (Fig. 2a). The Arbuckle formation is modeled as an isotropic and 119 homogeneous porous medium with permeability of $5 \times 10^{-13} \mathrm{~m}^{2}$ (Fig. 2b). The Precambrian

120 basement is discretized as a dual continuum ( 2 vol. \% fracture domain) to separately account for 121 fracture and matrix flow. Basement fracture permeability $(k)$ decays with depth $(z)$ in accordance 122 with the Manning and Ingebritsen (1999) equation: $k(z)=k_{0}\left(z / z_{0}\right)^{-3.2}$. For this model, $z_{0}$ 123 corresponds with the depth of the Arbuckle-basement contact $(2,300 \mathrm{~m})$, where fracture 124 permeability is estimated to be $1 \times 10^{-13} \mathrm{~m}^{2}$. As a result, the volume-weighted effective (bulk) 125 permeability ranges from $2 \times 10^{-15} \mathrm{~m}^{2}$ at the Arbuckle-basement interface to $2 \times 10^{-17} \mathrm{~m}^{2}$ at $10 \mathrm{~km}$ 126 depth (Fig. 2b). These effective permeability values are congruent with basement permeability 127 values reported in the literature for northern and central Oklahoma (Keranen et al., 2014; Goebel 128 et al., 2017). Because permeability within the Precambrian basement is highly uncertain, three 129 additional permeability scenarios are tested for $k\left(z_{0}\right)$ equal to $5 \times 10^{-13} \mathrm{~m}^{2}, 5 \times 10^{-14} \mathrm{~m}^{2}$, and $1 \times$ $13010^{-14} \mathrm{~m}^{2}$ (Fig. S1 of the electronic supplementary material (ESM)). The remaining hydraulic and 131 thermal parameters are listed in Table 1.

Table 1: Model Parameters

\begin{tabular}{lcccccccc}
\hline Medium & $\begin{array}{c}k \text {-matrix } \\
\left(\mathrm{m}^{2}\right)\end{array}$ & $\begin{array}{c}k \text {-fracture } \\
\left(\mathrm{m}^{2}\right)\end{array}$ & $\begin{array}{c}\text { Porosity } \\
-\end{array}$ & $\begin{array}{c}\text { Density } \\
\left(\mathrm{kg} \mathrm{m}^{-3}\right)\end{array}$ & $\begin{array}{c}\beta \\
\left(\mathrm{Pa}^{-1}\right)\end{array}$ & $\begin{array}{c}k_{\mathrm{T}} \\
\left(\mathrm{W} \mathrm{m}^{-1}{ }^{\circ} \mathrm{C}^{-1}\right)\end{array}$ & $\begin{array}{c}c_{\mathrm{p}} \\
\left(\mathrm{J} \mathrm{kg}^{-1}{ }^{\circ} \mathrm{C}^{-1}\right)\end{array}$ & $\begin{array}{c}D \\
\left(\mathrm{~m}^{2} \mathrm{~s}^{-1}\right)\end{array}$ \\
\hline Arbuckle & $5 \times 10^{-13}$ & - & 0.1 & 2,500 & $1.7 \times 10^{-10}$ & 2.2 & 1,000 & - \\
Basement & $1 \times 10^{-20}$ & $\mathrm{f}(z)$ & 0.1 & 2,800 & $4.5 \times 10^{-11}$ & 2.2 & 1,000 & - \\
Brine & - & - & - & $1123^{\dagger}$ & - & - & - & $1.14 \times 10^{-9}$ \\
Water & - & - & - & - & - & - & - & $2.30 \times 10^{-9}$ \\
\hline
\end{tabular}

$\dagger$ Reference density for EOS7. $k$-permeability. $\beta$-compressibility. $k_{\mathrm{T}}$-thermal conductivity. $c_{\mathrm{p}}$-heat capacity. $D$-diffusion coeff. 
To compare pressure accumulation between a single isolated injection well and multiple

133 closely spaced injection wells, this study considers two oilfield wastewater disposal scenarios: (1)

134 an individual well operating within the upper $200 \mathrm{~m}$ of the Arbuckle formation at 2,080 $\mathrm{m}^{3}$ day $^{-1}$

135 (13,000 US barrels (bbl) day $\left.{ }^{-1}\right)$, and (2) a well field comprising nine injection wells with $6 \mathrm{~km}$ 136 spacing, each operating at 2,080 $\mathrm{m}^{3}$ day $^{-1}\left(13,000 \mathrm{bbl} \mathrm{day}^{-1}\right)$. All model scenarios simulate 10 137 years of oilfield wastewater disposal followed by 10 years of post-injection fluid pressure 138 recovery. These models also account for variable fluid composition, which has been shown to 139 drive fluid pressure transients deeper into the seismogenic zone even after injection operations cease (Pollyea et al., 2019). The wastewater is representative of brine produced from the 141 Mississippi Lime formation, which is reported to have a mean total dissolved solids (TDS) 142 concentration of 207,000 ppm (Blondes et al., 2017). This TDS concentration corresponds with a 143 fluid density of $1,123 \mathrm{~kg} \mathrm{~m}^{-3}$ at conditions $\left(21 \mathrm{MPa}\right.$ and $\left.40^{\circ} \mathrm{C}\right)$ representative of the disposal 144 reservoir (Mao \& Duan, 2008). Fluid composition within the Precambrian basement is based on 145 data from south-central Kansas, which indicate that the mean TDS concentration is $107,000 \mathrm{ppm}$ 146 (Blondes et al., 2017) with corresponding fluid density of $1,068 \mathrm{~kg} \mathrm{~m}^{-3}$ at $21 \mathrm{MPa}$ and $40^{\circ} \mathrm{C}(\mathrm{Mao}$ 147 \& Duan, 2008).

The initial temperature distribution is calculated on the basis of a $40 \mathrm{~mW} \mathrm{~m}^{-2}$ heat flux reported for Oklahoma (Cranganu et al., 1998). This heat flux results in a geothermal gradient of $15018^{\circ} \mathrm{C} \mathrm{km}^{-1}$. Initial fluid pressure is $21 \mathrm{MPa}$ in the Arbuckle formation and increases as the product 151 of depth, gravitational acceleration, and fluid density, the latter of which is dependent on the 152 thermal gradient. Dirichlet conditions are specified in the far field to maintain the initial pressure 153 and temperature gradients along the lateral boundaries. Adiabatic pressure boundaries are 154 specified across the top and bottom of the domain on the basis of low permeability shale overlying 155 the Arbuckle formation and exceedingly low permeability at $\sim 10 \mathrm{~km}$ depth. The basal boundary 156 also imposes the $40 \mathrm{~mW} \mathrm{~m}^{-2}$ regional heat flux as a Neumann condition. Adiabatic boundaries are 157 also specified in the $x z$ - and $y z$-planes through the origin to facilitate the symmetry boundaries.

158 The code selection for this study is TOUGH3 (Jung et al., 2017) compiled with equation 159 of state module EOS7 for simulating non-isothermal mixtures of pure water and brine with mixing 160 by advective transport and molecular diffusion. The TOUGH3 simulator solves the governing 161 equations for mass and heat flow with parallel numerical solvers (PetSc), which allows for 
162 extremely high-resolution numerical simulation. The complete solution scheme for TOUGH3 is 163 presented in the TOUGH3 User's Guide (Jung et al., 2018), and summarized in the context of fully 164 saturated flow in Section S2 of the ESM.
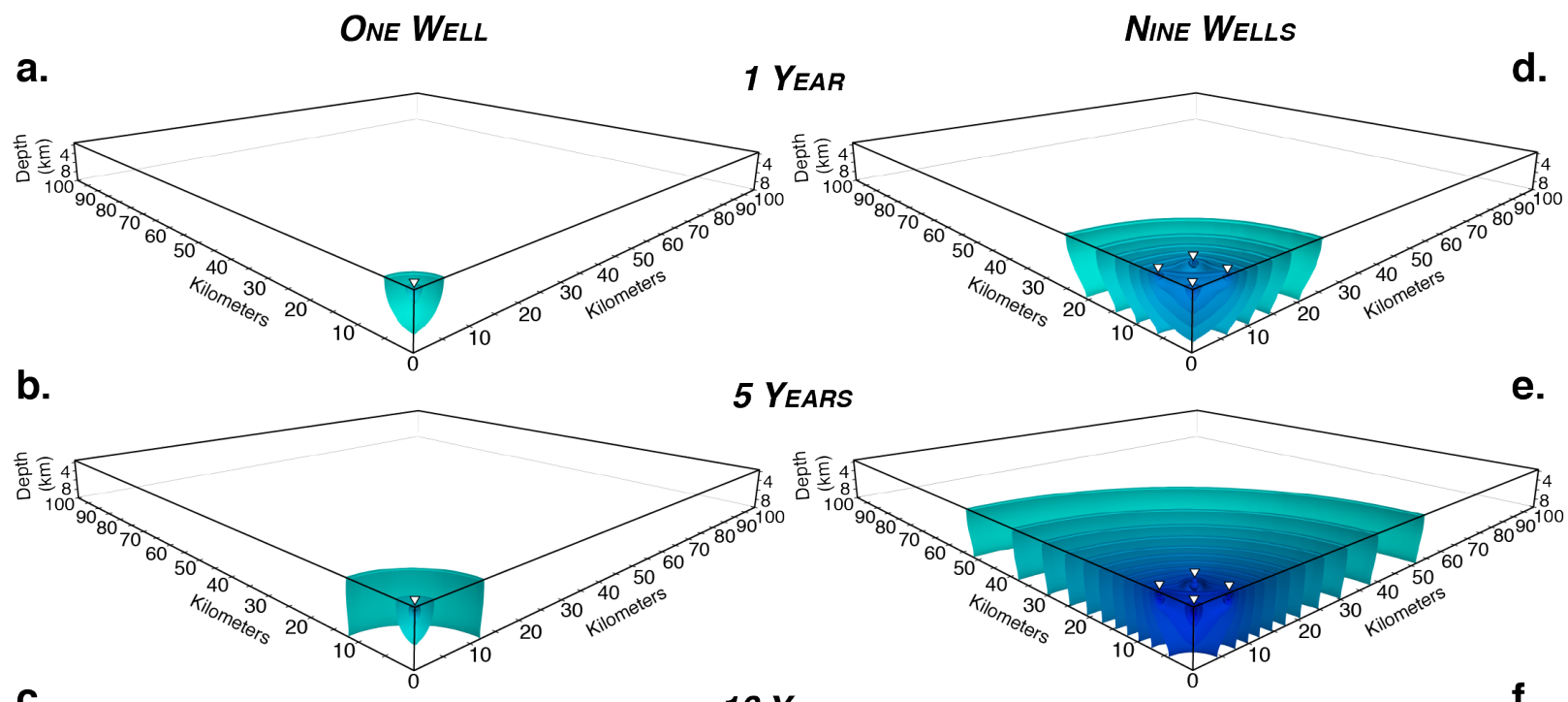

C.

10 YeARS

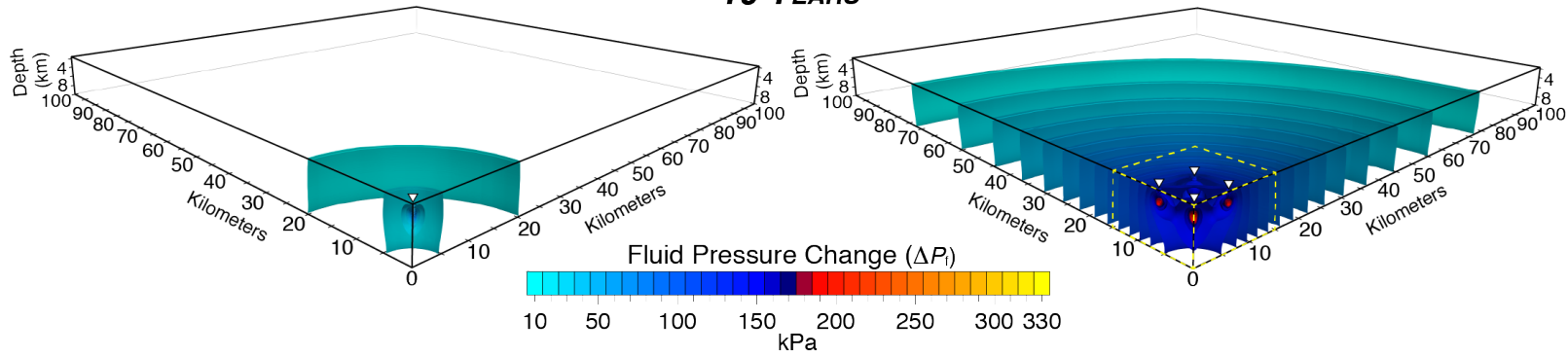

Figure 3: Simulated fluid pressure accumulation $\left(\Delta \mathrm{P}_{\mathrm{f}}\right)$ in 10-kPa contours for the one-well model (left column) and nine-well model (right column) after 1 year (a, d), 5 years (b, e), and 10 years (c, f) of oilfield wastewater disposal at 2,080 $\mathrm{m}^{3}$ day $^{-1} \mathrm{well}^{-1}$ $\left(13,000 \mathrm{bbl} \mathrm{day}^{-1}\right.$ well $\left.^{-1}\right)$. Injection occurs in the upper $200 \mathrm{~m}$ of the Arbuckle formation. Well positions are denoted with inverted triangles. All simulations invoke four-fold symmetry and only a $1 / 4$-domain is simulated. Yellow dashed box in (f) is presented in Figure 5 and animated in Movie S1 of the ESM.

\section{Results}

166 Model results are analyzed on the basis of fluid pressure above initial conditions $\left(\Delta P_{\mathrm{f}}\right)$ and plotted 167 as $\Delta P_{\mathrm{f}}$ isosurface contours in $10 \mathrm{kPa}$ intervals. Figure 3 presents simulation results during the 168 injection phase after 1, 5, and 10 years for both the single well and nine-well scenarios. Figure 4 169 presents simulation results during the post-injection recovery phase after 1,5 , and 10 years for 170 both the single well and nine-well scenarios. Figure 5 illustrates the hydrogeologic principle of 171 superposition within a detailed section of the nine-well simulation results after 10 years of injection. Electronic Supplementary Information include simulation results for the three additional 
173 models with varying permeability structure (Figs. S2 - S4 of the ESM) and Movie S1 of the ESM 174 presents animated simulation results for the detailed section shown in Figure 5.

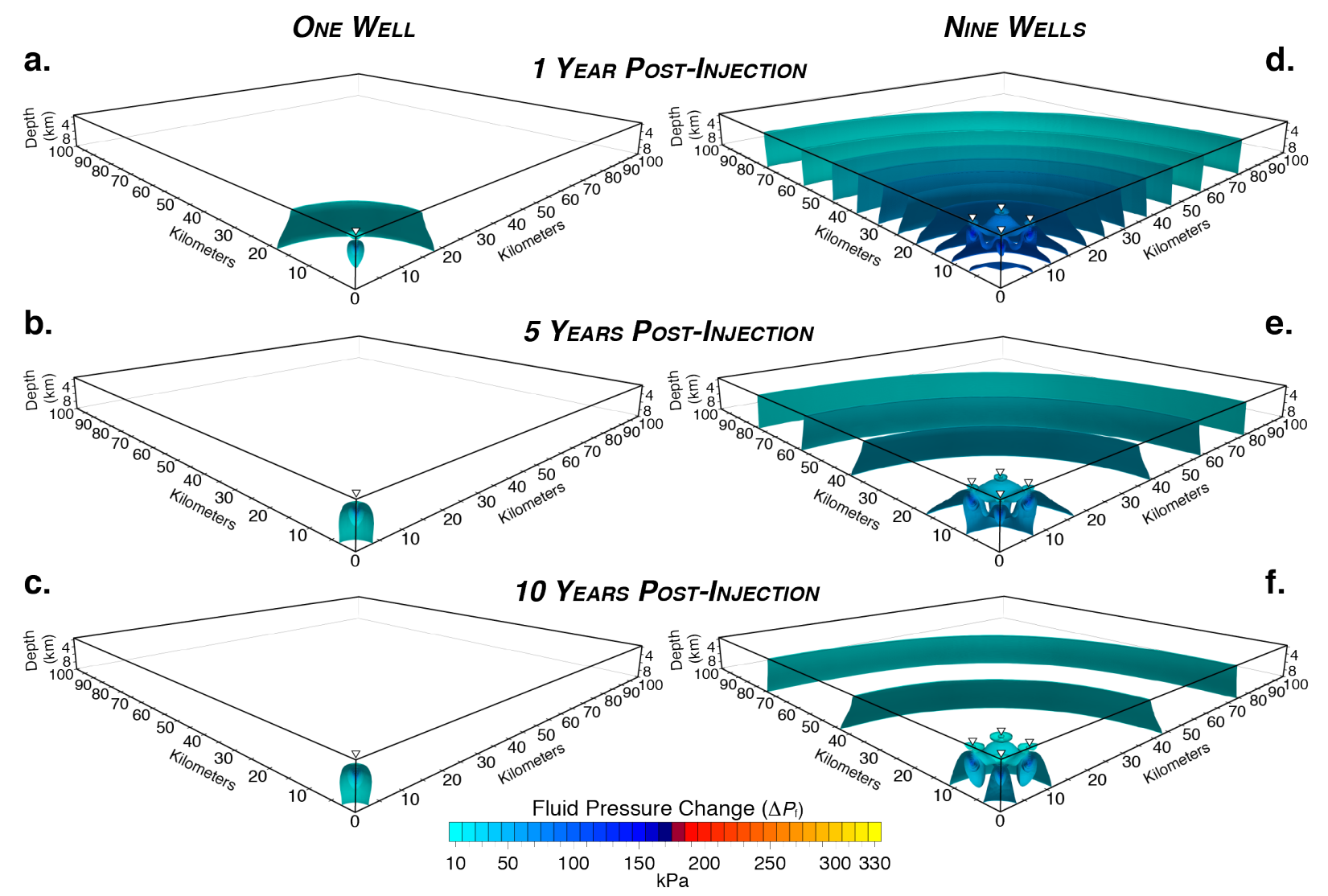

Figure 4: Isosurface contours of fluid pressure above initial conditions $\left(\Delta \mathrm{P}_{\mathrm{f}}\right)$ in 10-kPa contours for the single well model (left column) and nine-well model (right column) after 1 year (a, d), 5 years (b, e), and 10 years (c, f) of post-injection recovery. Well positions are denoted with inverted triangles. All simulations invoke four-fold symmetry and only a $1 / 4$-domain is simulated.

\section{Discussion}

176 Fluid pressure changes as low as $10 \mathrm{kPa}(0.1$ bar $)$ have been implicated in earthquake triggering

177 (Reasenberg \& Simpson, 1992). Results from the present study show that a single high-rate 178 injection well can drive a $10 \mathrm{kPa}$ pressure front to lateral distances of 5, 12, and $20 \mathrm{~km}$ from the 179 injection well after 1, 5, and 10 years, respectively (Fig. 3a-c). This result is congruent with many 180 research studies that show injection-induced earthquakes generally occur within $\sim 20 \mathrm{~km}$ of 181 injection operations, e.g., Yeck et al., (2014). In contrast, the model scenario simulating the effects 182 of nine high-rate injection wells drives the $10 \mathrm{kPa}$ pressure front beyond 20, 50, and $70 \mathrm{~km}$ from 183 the well cluster after 1, 5, and 10 years, respectively (Fig. 3d-f). The phenomenon in which 184 multiple injection wells drives long-range pressure transients is consistent across the complete set 
185 of basement permeability scenarios (Fig. 3, S2 - S4 of the ESM), which suggests that the lateral 186 extent of long-range pressure transients is generally insensitive to basement permeability. 187 Nevertheless, these results show that basement permeability does influence the shape of the 188 migrating pressure front. Within the highest permeability scenario (Fig. S2 of the ESM), fluid 189 pressure tends to advance uniformly throughout the seismogenic zone. In contrast, the lower 190 permeability scenarios (Fig. 3, S3 - S4 of the ESM) show that pressure accumulation reaches 191 greater lateral extent at shallow depths because the lower permeability structure inhibits pressure 192 propagation at greater depth. This effect is increasingly pronounced for the sequentially decreasing 193 permeability scenarios. The influence of basement permeability is most pronounced during post194 injection pressure recovery, when the absence of continued loading causes the far-field pressure 195 to front collapse around the injection well(s) (Fig. 4). Results from this study also show that lower 196 permeability scenarios delay pressure recovery, thus maintaining elevated fluid pressure long after 197 injection operations cease (Figs. S3 - S4 of the ESM).

198 In comparing the lateral extent of pressure propagation between the single- and nine-well 199 model scenarios, it is important to note that the nine-well model scenario injects $9 \times$ more 200 wastewater into the system than the single well scenario. This results in a proportionately greater 201 dynamic load and reasonably explains why the nine-well scenario generates higher fluid pressure 202 over longer distances. However, the discrepancy in wastewater injection volume between each 203 scenario does not explain how pressure transients from individual wells in the nine-well scenario 204 contribute to the cumulative pressure front. For example, the fluid pressure generated from each 205 well in the nine-well scenario (Fig. 3d-f) is identical to the pressure response radiating from the 206 single-well scenario (Fig. 3a-c) because all wells operate at 2,080 $\mathrm{m}^{3}$ day $^{-1}$. If the pressure fronts 207 from each well in the nine-well scenario propagate independent of one another, then the cumulative 208 pressure front would simply translate the single-well pressure front to each well location in the 209 nine-well scenario. This would put the $10-\mathrm{kPa}$ isosurface contour approximately $25-30 \mathrm{~km}$ from 210 the central well after 10 years because wells in the nine-well scenario are spaced $6 \mathrm{~km}$ apart. 211 However, the pressure front radiating from the nine-well model is more than twice this distance, 212 which suggests that the pressure fronts radiating from each individual well are interacting with one 213 another in a manner that compounds individual pressure fronts into a larger cumulative effect. This 214 phenomenon is present in previous modeling studies that show or mention coalescing pressure 
215 fronts (e.g., Keranen et al., 2014; Goebel et al., 2017), but the fundamental hydrogeological

216 process responsible this phenomenon has not been clearly articulated in the literature.

217 In groundwater hydraulics, the compounding nature of hydrogeological perturbations is 218 based on the principle of superposition, which states that "...the solution to a problem involving 219 multiple inputs is equal to the sum of the solutions to a set of simpler individual problems that 220 form the composite problem" (Reilly et al., 1984). This means that the groundwater response to 221 multiple pumping wells is the sum of the groundwater response for each individual well. As a 222 consequence, the cumulative effect of multiple pumping wells is additive. The principle of 223 superposition is traditionally taught in undergraduate hydrogeology courses in the context of 224 groundwater withdrawals, e.g., capture zone analysis, image well analysis, time-drawdown pump 225 test analysis (Fitts, 2012). In this context, superposition explains why drawdown increases faster 226 when there is an intersection between cones of depression from nearby pumping wells. In the 227 context of oilfield wastewater disposal, this concept is simply inverted so that pressure 228 accumulates faster when pressure fronts from nearby injection wells intersect one another. The 229 additive nature of superposition means that the hydraulic gradient locally increases when pressure 230 fronts intersect and merge. This increases the energy potential within the groundwater system, 231 which drives pressure transients longer distances than estimates predicted by either single-well 232 models or triggering front calculations based on classical root-time scaling laws for pressure 233 diffusion from individual wells.

234 To illustrate how the principle of superposition drives long-range pressure accumulation, 235 Figure 5 presents a detailed section of the nine-well model after 10 years of injection and Movie 236 S1 shows its temporal progression in 6-month intervals from $3-10$ years. These graphics show 237 that pressure fronts nucleate at injection wells, radiate laterally, and then merge to produce a 238 volume of overpressure that encompasses a greater areal extent than is possible for individual wells 239 operating in isolation. As this process continues, the cumulative result is long-range pressure 240 diffusion that continues so long as the dynamic load is maintained from the injection wells. To 241 further explore the nature of superposition, the nine-well model was repeated so that each well 242 injects $231 \mathrm{~m}^{3}$ day $^{-1}\left(1,444 \mathrm{bbl} \mathrm{day}^{-1}\right)$, which results in a total injection volume of 2,080 $\mathrm{m}^{3}$ day $^{-1}$ $243\left(13,000 \mathrm{bbl} \mathrm{day}^{-1}\right)$. This effectively distributes the total injection volume from the single-well 244 model evenly across the nine-well model. Results for this simulation (Fig. S5 of the ESM) show 
245 that the $10 \mathrm{kPa}$ pressure front reaches the same lateral extent $(\sim 20 \mathrm{~km})$ as the single well model 246 (Fig. 3) after 10 years of injection; however, this result also finds that fluid pressure recovers much 247 faster when the injection volume is distributed over a larger area. In the context of injection248 induced earthquake hazard mitigation, this result demonstrates that total volume of wastewater 249 injected is a more fundamental control on long-range fluid pressure transients than the total number 250 of injection wells; however, it is also clear that distributing a given wastewater volume over 251 multiple wells results in faster post-injection fluid pressure recovery.

252 Because this modeling study is based on the injection rates and geology from the Anadarko 253 Shelf near the Oklahoma-Kansas border, the principle of superposition reasonably explains the 254 observations of long-range pressure transients and earthquake triggering reported in south-central

255 Kansas by Peterie et al. (2018). This

256 inference is further supported by the 257 spatial distribution of wastewater 258 injection wells in Alfalfa County, 259 Oklahoma, which experienced a dramatic 260 increase in the number of wastewater 261 disposal wells and M3+ earthquakes 262 between 2011 and 2015 (Fig. 6). In 2011, 263 the spatial distribution of wastewater 264 injection wells was relatively sparse and 265 there was only one high-rate injector (> $2662,000 \mathrm{~m}^{3}$ day $\left.^{-1}\right)$. By 2015, the mean 267 nearest-neighbor distance between 268 injection wells was less than $1.5 \mathrm{~km}$, and 269 there were 17 high-rate injection wells 270 (Fig. 6, red circles). The simulations 271 presented here suggest that pressure

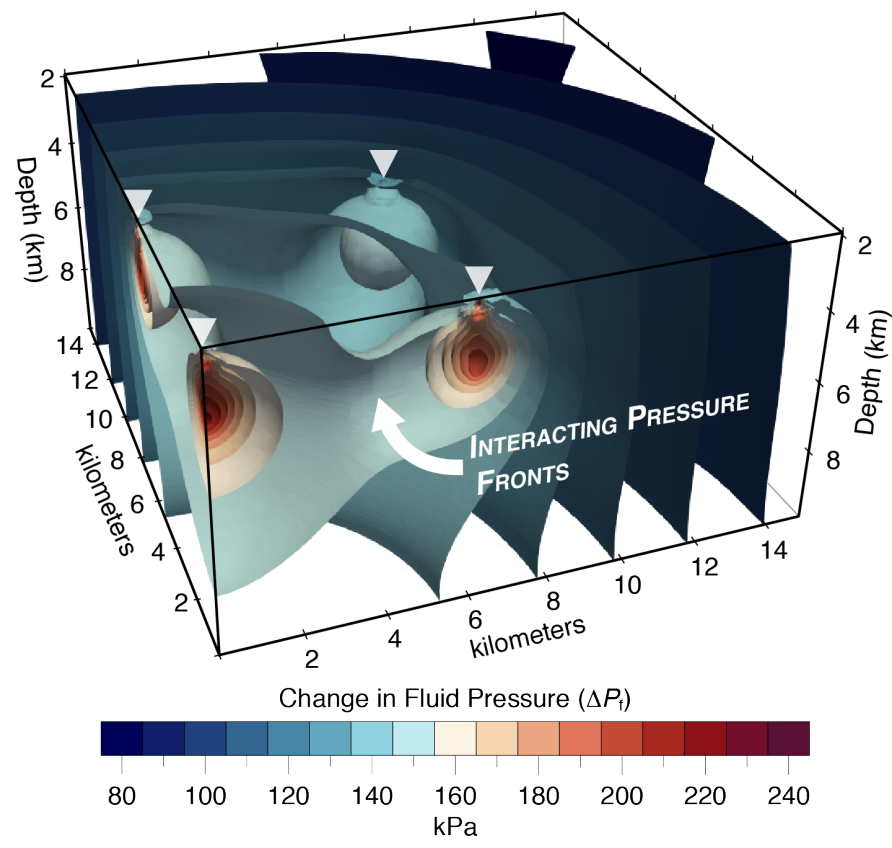

Figure 5: Detailed section of callout in Figure $3 f$ showing the hydrogeological principle of superposition as interacting pressure fronts that locally increase the hydraulic gradient to drive long-range pressure accumulation. Isosurface contours illustrate fluid pressure above initial conditions $\left(\Delta \mathrm{P}_{\mathrm{f}}\right)$ in $10-\mathrm{kPa}$ isosurface contours. Inverted triangles denote well locations. Movie S1 of the ESM presents an animation of pressure propagation within the section illustrated here. Note model invokes fourfold symmetry, so only $1 / 4$ domain is shown and color ramp is restricted to the $\Delta \mathrm{P}_{\mathrm{f}}$ range for this section of the model.

272 fronts radiating from numerous, closely spaced high-rate injection wells at the Oklahoma-Kasas

273 border are merging to drive long-range pressure accumulation into south-central Kansas.

In the post-injection recovery phase, the simulations developed here also show that fluid 275 pressure continues increasing at systematically greater depths as high-density wastewater sinks 


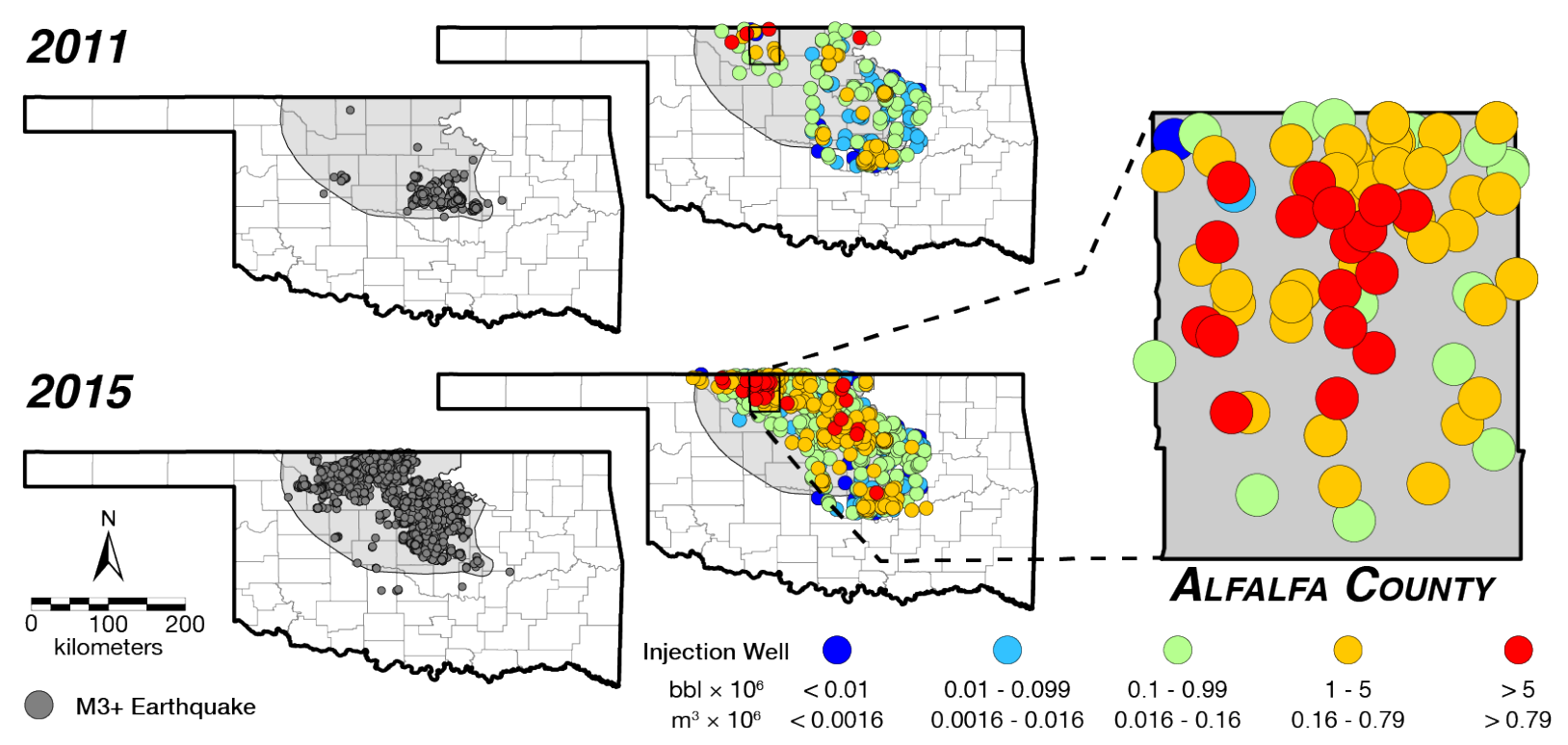

Figure 6: North-central Oklahoma experienced dramatic growth in the number of oilfield wastewater disposal wells and M3+ earthquakes from 2011 to 2015. In Alfalfa County, the mean nearest-neighbor well spacing was less than $1.5 \mathrm{~km}$ in 2015 (Pollyea et al., 2018a). Earthquake data from USGS ComCat database (USGS, 2019) and wastewater disposal data from Oklahoma Corporation Commission (OCC, 2018).

and displaces lower density host rock fluids (Fig. 4d-f). This phenomenon has been implicated in systematically decreasing earthquake hypocenter depths in northern Oklahoma and southern Kansas (Pollyea et al., 2019). The simulation results presented here further indicate that the principle of superposition explains how these residual pressure fronts merge to produce a region of elevated fluid pressure that systematically deepens even after injection operations cease (Fig 4d-f).

Whereas previous studies allude to "merging" or "coalescing" pressure fronts during oilfield wastewater disposal (e.g., Goebel et al., 2017), this study shows that the hydrogeological principle of superposition is the mechanistic process responsible for this phenomenon. Moreover, this study shows that the principle of superposition reasonably explains how a well field comprising just nine closely spaced, high-rate injection wells can drive long-range fluid pressure transients to $70+\mathrm{km}$ from the well cluster. And while this may seem intuitive to the trained

288 hydrogeologist, there has yet to be a thorough examination of the hydrogeological processes governing long-range pressure transients. As a consequence, statistical analyses of long-range earthquake triggering (Pollyea et al., 2018a) are met with skepticism (Wilmoth, 2018) and observations of long-range fluid pressure do not have a defensible mechanistic explanation (Peterie 
293 of culpability when injection-induced earthquakes cause damage. Specifically, who is responsible

294 if one wastewater injection well pumps for years without seismicity, and then a second (or third,

295 fourth $, \ldots, n^{\text {th }}$ ) comes online and earthquakes begin? Of course, the first operator will argue that

296 years passed without incident, so responsibility must lie with the other operators. Yet the principle

297 of superposition implies that the question of culpability is much more complex because the 298 cumulative effects of multiple injection wells are additive.

\section{Conclusions}

300 This study demonstrates that the hydrogeologic principle of superposition is the mechanistic 301 process governing long-range fluid pressure transients during oilfield wastewater disposal. The 302 principle of superposition states that the cumulative effects of multiple pumping wells are additive. 303 This phenomenon is demonstrated by interrogating results from a hypothetical numerical 304 groundwater model with geological, thermal, and fluid properties typical of the Anadarko Shelf 305 region in north-central Oklahoma and south-central Kansas. The models are used to compare fluid 306 pressure transients radiating from an isolated wastewater injection well and a well-field comprising 307 nine closely spaced injection wells. Results from this study are summarized below:

308 1. When wastewater injection wells are closely spaced, their pressure fronts interact and merge to locally increase the hydraulic gradient and drive long-range fluid pressure transients, i.e., the principle of superposition is the mechanistic explanation for long-range fluid pressure transients during regionally expansive oilfield wastewater disposal operations.

2. The cumulative effects of just nine injection wells can drive a $10 \mathrm{kPa}$ pressure front to length scales exceeding $70 \mathrm{~km}$ from the well cluster. Because there are hundreds of wastewater disposal wells operating in Oklahoma and Kansas, the hydrogeologic principle of superposition reasonably explains (i) observations of long-range $(90+\mathrm{km})$ fluid pressure accumulation reported by Peterie et al. (2018) and (ii) regional-scale $(100+\mathrm{km})$ joint spatial correlation between wastewater injection volume and earthquake occurrence reported by Pollyea et al., (2018a).

3. Long-range fluid pressure transients are governed by cumulative injection volume, rather than the number of injection wells within a given disposal reservoir; however, post- 
injection pressure recovery occurs faster when wastewater volume is distributed across multiple injection wells. Thus, more low-rate injection wells are likely better practice than individual high-rate injection wells for the same cumulative injection volume.

327 In closing, the hypothetical models developed for this study comprise idealized geology that 328 neglects detailed fault structures and hydro-mechanical couplings that are known to influence 329 earthquake triggering processes. Nevertheless, this study does account for several hydrogeological 330 phenomenon that are now known to be critically important to fluid pressure accumulation and 331 recovery, specifically thermal effects on fluid flow and variable fluid composition between 332 wastewater and host rock (Pollyea et al., 2019). As a result, this modeling study provides the 333 hydrogeological basis to apply the principle of superposition as a framework to understand and 334 deconvolve complex interactions between pressure transients when numerous wastewater 335 injection wells operate in close spatial proximity. The application of these methods to real world 336 sites requires substantial advances in (i) the ability to characterize complex geologic features and

337 their hydraulic properties within the seismogenic zone, (ii) availability and access to fluid property 338 datasets within the seismogenic zone, and (iii) efficient numerical simulation frameworks for 339 modeling fully coupled thermal, hydraulic, chemical, and mechanical processes. The author hopes 340 the discussion presented in this manuscript yields additional motivation to pursue these objectives.

\section{Acknowledgments, Samples, and Data}

342 The author extends sincerest gratitude to Dr. Martin C. Chapman for insightful discussions about 343 injection-induced seismicity. Computational resources were provided by Advanced Research 344 Computing at Virginia Tech. The author also thanks Dr. Stuart Gilfillan and one anonymous 345 reviewer for their thoughtful reviews of this manuscript. This study is based upon work supported 346 by the U.S. Geological Survey under Grant No. G19AP00011. The views and conclusions 347 contained in this document are those of the authors and should not be interpreted as representing 348 the opinions or policies of the U.S. Geological Survey. Mention of trade names or commercial 349 products does not constitute their endorsement by the U.S. Geological Survey. The author declares no conflict of interest. 


\section{References}

352 Blondes, M., Gans, K.D., Engle, M.A., Kharaka, Y.K., Reidey, M.E., Saraswathula, Y., Thordsen, 353 J.J., Rowan, E.L., and Morrissey, E.A. 2017. USGS National Produced Waters Geochemical 354 Database v2.3. Accessed 13 June 2018 at https://energy.usgs.gov/Portals/0/Rooms/produced 355 wat ers/tabular/USGSPWDBv2.3c.csv

356 Brown, M.R., Ge, S., Sheehan, A.F. and Nakai, J.S., 2017. Evaluating the effectiveness of induced 357 seismicity mitigation: Numerical modeling of wastewater injection near Greeley, 358 Colorado. Journal of Geophysical Research: Solid Earth, 122(8), pp.6569-6582.

Cranganu, C., Lee, Y. and Deming, D., 1998. Heat flow in Oklahoma and the south-central United States. Journal of Geophysical Research: Solid Earth, 103(B11), pp.27107-27121.

Ellsworth, W.L., 2013. Injection-induced earthquakes. Science, $341(6142)$. doi:10.1126/science.1225942.

Fitts, C.R., 2012. Groundwater Science, $2^{\text {nd }}$ Edition. Elsevier.

Goebel, T.H. and Brodsky, E.E., 2018. The spatial footprint of injection wells in a global compilation of induced earthquake sequences. Science, 361(6405), pp.899-904.

Goebel, T.H.W., Weingarten, M., Chen, X., Haffener, J. and Brodsky, E.E., 2017. The 2016 Mw5.

Hearn, E.H., Koltermann, C. and Rubinstein, J.R., 2018. Numerical models of pore pressure and stress changes along basement faults due to wastewater injection: Applications to the 2014 Milan, Kansas earthquake. Geochemistry, Geophysics, Geosystems. doi:10.1002/2017GC007194.

Herbert, A., Jackson, C., Lever, D. 1988. Coupled groundwater flow and solute transport with fluid

Hubbert, M.K. and Willis, D.G., 1957. Mechanics of Hydraulic Fracturing, 210. Petroleum Transactions, AIME. 
Johnson, K. S. 1991. Geologic overview and economic importance of Late Cambrian and Ordovician age rocks in Oklahoma, in Johnson, K. S., ed., Late Cambrian-Ordovician geology of the southern Midcontinent, 1989 Symposium: Oklahoma Geological Survey, Circular 92, p. 3-14.

Jung, Y., Pau, G. S. H., Finsterle, S., \& Pollyea, R. M., 2017. TOUGH3: A new efficient version of the TOUGH suite of multiphase flow and transport simulators. Computers \& Geosciences. v. 108, p. 2-7, November. doi:10.1016/j.cageo.2016.09.009.

Jung, Y., Pau., G., Finsterle, S., and Doughty, C. 2018. TOUGH3 User's Guide: Version 1.0, Tech. Rep. LBNL-2001093 Lawrence Berkeley National Laboratory, January. Available online at: http://tough.lbl.gov/assets//files/Tough3/TOUGH3_Users_Guide_v2.pdf

Keranen, K.M., Weingarten, M., Abers, G.A., Bekins, B.A. and Ge, S., 2014. Sharp increase in central Oklahoma seismicity since 2008 induced by massive wastewater injection. Science, 345(6195), pp.448-451.

Keranen, K.M., Savage, H.M., Abers, G.A. and Cochran, E.S., 2013. Potentially induced earthquakes in Oklahoma, USA: Links between wastewater injection and the $2011 \mathrm{Mw} 5.7$ earthquake sequence. Geology, 41(6), pp.699-702.

Langenbruch, C., Weingarten, M. and Zoback, M.D., 2018. Physics-based forecasting of manmade earthquake hazards in Oklahoma and Kansas. Nature Communications, 9(1), p.3946.

Manning, C.E. and Ingebritsen, S.E., 1999. Permeability of the continental crust: Implications of geothermal data and metamorphic systems. Reviews of Geophysics, 37(1), pp.127-150.

Mao, S. and Duan, Z., 2008. The PVT properties of aqueous chloride fluids up to high temperatures and pressures. J. Chem. Thermodyn., 40, pp.1046-1063.

National Research Council (NRC). 2013. Induced Seismicity Potential in Energy Technologies. National Academies Press, Washington D.C. doi:10.17226/13355

OCC, 2018. Oil and Gas Data Files, Oklahoma Corporation Commission (OCC), Available online at: http://www.occeweb.com/og/ogdatafiles2.htm (Last Accessed 23 December).

Ogwari, P. O., DeShon, H. R., \& Hornbach, M. J. 2018. The Dallas-Fort Worth airport earthquake sequence: Seismicity beyond injection period. Journal of Geophysical Research: Solid Earth, 123(1), 553-563. 
Peterie, S.L., Miller, R.D., Intfen, J.W. and Gonzales, J.B., 2018. Earthquakes in Kansas Induced by Extremely Far-Field Pressure Diffusion. Geophysical Research Letters, 45(3), pp.13951401.

Pollyea, R.M., Chapman, M.C., Jayne, R.S. and Wu, H., 2019. High density oilfield wastewater disposal causes deeper, stronger, and more persistent earthquakes. Nature Communications, 10. doi:10.1038/s41467-019-11029-8.

413 Pollyea, R.M., Mohammadi, N., Taylor, J.E. and Chapman, M.C., 2018a. Geospatial analysis of 414 Oklahoma (USA) earthquakes (2011-2016): Quantifying the limits of regional-scale earthquake mitigation measures. Geology, Vol. 46, No. 3, p. 715-718. doi: 10.1130/G39945.1.

416 Pollyea, R.M., Jayne, R.S., and Wu, H. 2018b. The effects of fluid density variations during oilfield 417 wastewater disposal. In Proceedings of the TOUGH Symposium 2018, Ed. Oldenburg, C.

Pruess,K. Oldenburg, C., and Moridis, G. 2012. TOUGH2 User's Guide Version 2, Tech. Rep. LBNL-43134 Lawrence Berkeley National Laboratory. Available online at:

Raleigh, C.B., Healy, J.H. and Bredehoeft, J.D., 1976. An experiment in earthquake control at Rangely, Colorado. Science, 191(4233), pp.1230-1237.

Reilly, T.E., Franke, O.L., and Bennett, G.D. 1984. The principle of superposition and its

Reasenberg, P.A. and Simpson, R.W., 1992. Response of regional seismicity to the static stress change produced by the Loma Prieta earthquake. Science, 255(5052), pp.1687-1690. application in groundwater hydraulics. United States Geological Survey, Reston, Virginia. Open File Report 84-459. doi:10.3133/ofr84459. (Accessed online 19 December 2018 at https://pubs.usgs.gov/of/1984/0459/report.pdf)

Schoenball, M., Walsh, F. R., Weingarten, M., \& Ellsworth, W. L. 2018. How faults wake up: the Guthrie-Langston, Oklahoma earthquakes. The Leading Edge, 37(2), 100-106.

Shapiro, S.A., Krüger, O.S., Dinske, C. and Langenbruch, C., 2011. Magnitudes of induced earthquakes and geometric scales of fluid-stimulated rock volumes. Geophysics, 76(6), pp.WC55-WC63. 
435 U.S. Geological Survey (USGS), 2019. ANSS Comprehensive Earthquake Catalog (ComCat): $436 \quad$ https://earthquake.usgs.gov/earthquakes/search/ accessed 27 March 2019.

437 Walsh, F.R. and Zoback, M.D., 2015. Oklahoma's recent earthquakes and saltwater disposal. $438 \quad$ Science Advances, 1(5). doi:10.1126/sciadv.1500195.

439 Weingarten, M., Ge, S., Godt, J.W., Bekins, B.A. and Rubinstein, J.L., 2015. High-rate injection $440 \quad$ is associated with the increase in US mid-continent seismicity. Science, 348(6241), pp.1336$441 \quad 1340$.

442 Wilmoth, A. 2018. "Oklahoma researcher dismisses Virginia Tech study of local earthquakes." 443 The Oklahoman, Oklahoma City, Oklahoma: 11 January (Accessed 12 January 2018 at: 444 https://newsok.com/article/5579064/oklahoma-researcher-dismisses-virginia-tech-study-of$445 \quad$ local-earthquakes)

446 Yeck, W.L., Block, L.V., Wood, C.K. and King, V.M., 2014. Maximum magnitude estimations of 447 induced earthquakes at Paradox Valley, Colorado, from cumulative injection volume and 448 geometry of seismicity clusters. Geophysical Journal International, 200(1), pp.322-336.

449 Zoback, M.D. and Hickman, S., 1982. In situ study of the physical mechanisms controlling induced 450 seismicity at Monticello Reservoir, South Carolina. Journal of Geophysical Research: Solid $451 \quad$ Earth, 87(B8), pp.6959-6974. 